\title{
The Relationship Between Khat Use Disorder and Post-Traumatic Stress Disorder Among Prisoners with Life Time Trauma Exposure in Ethiopia: A Cross-Sectional Study
}

\author{
Asrat Wolde (iD \\ Department of Psychiatry, School of \\ Medicine, College of Medicine and Health \\ Sciences, Mizan Tepi University, Mizan \\ Aman, Ethiopia
}

\begin{abstract}
Background: Problematic khat use is an emerging health problem worldwide. Trauma experience, crime, and substance misuse is closely related. However, there is lack of evidence whether post-traumatic stress disorder (PTSD) and life time trauma exposure has a relationship with problematic khat use among prisoners in our country Ethiopia, or elsewhere. Therefore, this study assessed the relationship between PTSD and life time trauma exposure with khat use disorder among newly admitted prisoners in Bench Shako and West Omo zone correctional institution, Mizan Aman, Ethiopia.
\end{abstract}

Methods: A cross-sectional study was conducted among $411(\mathrm{~N}=422)$ prisoners from April 20 to July 19, 2019, by using a consecutive sampling technique. Trauma exposure and post-traumatic stress disorder were assessed with a life event check list and Posttraumatic stress disorder - civilian version (PCL-C), respectively. The WHO ASSIST tool was used to assess khat, alcohol, and tobacco use disorder. Antisocial personality disorder, criminal, and clinical history were also assessed. The data were entered into Epi-data version 3.1 and then exported to Statistical Package for Social Science version 21. A logistic regression model was used and variables with a $p$-value less than 0.05 in the final fitting model were stated as independent predictors of PTSD.

Results: Nearly one out of four prisoners exposed to life time trauma exposure developed PTSD, and the prevalence of khat use disorder among prisoners with life time trauma exposure and PTSD was $45 \%$ and $85 \%$, respectively. Prisoners with khat use disorder had more than 5 times higher odds of association with PTSD than their counterparts (AOR=5.3, 95\% $\mathrm{CI}=2.4-11.8)$. In addition, antisocial personality disorder $(\mathrm{AOR}=2.8,95 \% \mathrm{CI}=1.6-5.5)$, criminal recidivism $(\mathrm{AOR}=2.5,95 \% \mathrm{CI}=1.5-4.3)$, and being a driver $(\mathrm{AOR}=2,95 \% \mathrm{CI}=1.2-$ 3.3) were positively associated with PTSD.

Conclusion: Khat use disorder was higher among prisoners with life time trauma exposure and PTSD, and khat use disorder was positively associated with PTSD.

Keywords: trauma, post-traumatic stress disorder, prisoners, khat use disorder, crime, Ethiopia

\section{Background}

Khat trees are grown in Africa and the Arabian peninsula, and its leaf has a central and peripheral nervous system stimulant called cathinone: which is a natural amphetamine. ${ }^{1}$ Khat is an everyday drug for millions of people in Africa, ${ }^{2}$ and its consumption is rapidly growing in many western countries due to immigrants from
Department of Psychiatry, School of

Medicine, College of Medicine and Health

Sciences, Mizan Tepi University, Mizan

Aman, Ethiopia

Tel +251 916389179

Email Asratwolde2017@gmail.com 
Africa and Arabian countries. ${ }^{3}$ Khat-induced effects are feelings of increased energy, confidence to converse with others, decreased fatigue, and a general sense of wellbeing. ${ }^{3}$ The adverse effect of khat include: insomnia, gastric and liver disorders, cardiovascular disorder, periodontal problems, impotence, depression, hallucinations, dependence, and khat induced psychotic disorder. ${ }^{4-7}$ About 10 million people worldwide consume khat daily, ${ }^{8}$ and $12 \%$ of women and $27 \%$ of men have chewed khat in Ethiopia. $^{9}$

Prisoners had higher prevalence of trauma exposure and post-traumatic stress disorder than the general population. ${ }^{10}$ Post-traumatic stress disorder is a mental disorder caused by experiencing, witnessing, and learning the following traumatic events: sexual assault, torture, sudden death of a loved one, and natural disasters. ${ }^{11}$ Posttraumatic stress disorder increases criminal behavior through using substance to cope with the sequel of trauma. ${ }^{12}$ The study done on European prisoners found the highest prevalence of post-traumatic stress disorder among those in Finland (27.8\%) followed by Croatian (20.6\%), England (20.2\%), and Germany (18.4\%). ${ }^{13}$ The study done in South Africa showed that the prevalence of post-traumatic stress disorder was $9.8 \% .{ }^{14}$ According to DSM- 5 , the prevalence of life time trauma exposure is $89.7 \%{ }^{15}$ and trauma exposure ranged from 62.4 to $87.0 \%$ among incarcerated adult males. ${ }^{16-18}$

The study disclosed that $22 \%$ to $43 \%$ of patients with PTSD develop a substance use disorder in their life time, ${ }^{19}$ and comorbid post-traumatic stress disorder and substance use disorder is associated with many psychosocial complications and poor social support. ${ }^{20}$ PTSD was a risk factor for substance use relapse and poor treatment outcome. ${ }^{21,22}$ Self-medication hypothesis stated that individuals with post-traumatic stress disorder use psychoactive substances to deal with trauma-related unpleasant experiences. ${ }^{23}$ People use substance to suppress trauma symptoms, ${ }^{24}$ and patients with trauma consume substance to cope with sleep issues, feeling empty, and intrusive memories. ${ }^{25}$ Prisoners with a substance use disorder have a higher likelihood of having trauma because of their risky lifestyle. ${ }^{26,27}$ In addition, people with substance use disorder might increase vulnerability to trauma due to a poor coping mechanism or neurochemical brain changes due to substance misuse. ${ }^{28}$ Prisoners with post-traumatic stress disorder abuse substance to deal with trauma-related negative psychological and biological experiences, ${ }^{12}$ and this behavior can increase the chance of committing crime and recidivism due to the fact that the majority of criminal activities were performed while individuals were under the influence of substance. ${ }^{29,30}$ The data presented in this paper were obtained from the study on psychopathy and associated factors among newly admitted prisoners in a correctional institution located in Bench Shako and West Omo zone correctional institution, Mizan Aman, Ethiopia. ${ }^{27}$ Even though substance use disorder, association between alcohol and trauma, association between psychopathy and khat abuse, and psychopathy and associated factors among prisoners in Ethiopia were well established $^{31-34}$ up to date, the potential association between post-traumatic stress disorder and trauma exposure with problematic khat use among prisoners has not been investigated in our country Ethiopia, or elsewhere. Therefore, the aim of this study was to assess the association between life time trauma exposure and post-traumatic stress disorder with khat use disorder among newlyadmitted prisoners in Bench Shako and West Omo zone correctional institution, Mizan Aman, Ethiopia.

\section{Methods}

\section{Study Setting and Period}

The project was carried out from April to late July, 2019 in South Ethiopia, Bench Shako and West Omo zone correctional institution. The study area is located in the South West part of Ethiopia at a distance of $565 \mathrm{~km}$ from Addis Ababa, the capital city of Ethiopia. The study area is located around Dima mining site of Gambella Regional State, which is a known problematic substance use area, and most of the people who committed a crime escape from other parts of Ethiopia to this area. The prison center provides a service for Bench, Sheko, Sheka, Surma, Dizi, Minit, Kefa, and other ethnic groups of Ethiopia. According to the world prison brief data report by the institute for crime and justice policy research, Ethiopia had 110,000 pretrial detainees and remand prisoners. Among them, only 16,390 and 4620 were women pretrial detainees and remand prisoners, respectively. ${ }^{35}$ The correctional institution had 2025 sentenced prisoners and, among them, 128 were women prisoners at the time of study. The prison center had a clinic with no mental health clinician and service.

\section{Study Design and Population}

A cross-sectional study was carried out. All new prisoners admitted recently in Ethiopia were the source population while all new prisoners fulfilling eligibility criteria at data 
collection time were the study population. Any new prisoner admitted recently during the study period was included while prisoners with communication impairment due to psychiatric illness, prisoners who cannot give response due to physical illness, and those aged below 18 years were excluded.

\section{Sample Size Determination and Sampling Technique}

The sample size (n) was determined by using the single population proportion formula, by assuming a prevalence (p) of $50 \%$, since there was no a similar study carried out in our country among prisoners. Using a $95 \%$ confidence interval $(\mathrm{CI})$ and a margin of error $(\mathrm{d}=0.05)$, and a nonresponse rate of $10 \%$, the total sample size was 422 . A non-probability consecutive sampling technique was used. Any newly received prisoner was participated till the required numbers of prisoner were saturated. The newly received prisoners were interviewed within 24 hours' time period.

\section{Procedure}

Data were collected by using a pre-tested semi-structured questionnaire with a trained interviewer. The questionnaires were developed by using standardized tools from relevant literature review and translated to Amharic language, which is the official language of Ethiopia. In addition to interview, file review was used for antisocial personality disorder diagnosis, recidivism, and criminal history. Data collectors and supervisors were clinicians with mental health specialty. Training was given on ASSIST, Post-traumatic stress disorder - civilian version (PCL-C), DSM-V antisocial personality disorder diagnostic criteria, and other tools for data collectors and supervisors by a senior mental health specialist to assure data quality. A standard for scoring individual items of the questioner was checked before data collection. Furthermore, a pretest was carried out with $5 \%$ of the required sample size on a nearby prison center to minimize errors in data collection instruments.

The data collection instrument has the following parts: PTSD, life time trauma exposure, khat and other substance use history, ASPD, socio-demographic history, social support history, clinical history, and criminal history. Posttraumatic stress disorder -civilian version (PCL-C) was used to screen PTSD symptoms. It is a 17-item PTSD screening instrument used for individuals with any type of traumatic events. It is the most commonly used instrument in cross-cultural setting. PCL-C has 5-point likert scales from not at all (1) to extremely (5). The cut point of 44 and above was considered as a prisoner with PTSD. PCL has the sensitivity of 0.90 and a specificity of $0.88 .^{36-38}$

Khat use disorder was assessed by using the amphetamine version of the alcohol, smoking, and substance involvement screening test (ASSIST), ${ }^{1}$ which consists of the following components: life time khat use, frequency of khat use in the past three months, frequency of strong desire to get khat, frequency of financial, health, social, and legal complications due to khat use, whether khat use affects one's role and obligation, whether someone worried the client's pattern of khat use, and whether the client attempted to stop khat use. In order to score ASSIST, question two up to seven is added to get the khat use risk level. Those who scored 27 and above were considered as individuals with khat use disorder, and those who used khat in the past three months were considered current khat users. $^{39}$ The reliability (Cronbach's alpha) in this study was 0.91 .

The following standardized instruments were used in addition to the ASSIST tool as explanatory variables for PTSD: Oslo-3 social support scale, ${ }^{40}$ life event check list, ${ }^{41}$ and DSM-5 diagnostic criteria of antisocial personality disorder ${ }^{42}$ to assess prisoner's social support status, life time trauma exposure, and antisocial personality disorder, respectively. Social support status was assessed by using the Oslo-3 social support scale. According to the Oslo-3 social support scale; poor support 3-8, moderate support 9-11, and strong support $12-14 .{ }^{40}$ In addition, trauma exposure was assessed with the life events checklist. The prisoner has life time trauma exposure if the prisoner was exposed to at least one traumatic life event. The life event checklist was developed by the National Center of Post-traumatic Stress Disorder in order to detect post-traumatic stress symptoms. It was used in crosscultural settings and predictive of substance use disorder, anxiety symptoms, depression, and post-traumatic stress disorder. ${ }^{41}$ Antisocial personality disorder was assessed with DSM-5 diagnostic criteria of antisocial personality disorder. If a prisoner scored three or more of seven possible adulthood antisocial personality symptoms and three or more of childhood conduct disorder symptoms, the prisoner was positive for antisocial personality disorder. ${ }^{42}$ In addition to diagnostic criteria, file review was used to screen ASPD. 
In addition to standardized instruments, the following predictive variables were used: socio-economic and demographic variables, environmental-related variables like childhood trauma exposure, clinical-related variables (history of mental illness, history of known medical illness, known family mental illness, and history of family alcohol use), and crime-related variables were also assessed. The abovementioned factors were used because other studies showed that they were relevant for post-traumatic stress disorder.

\section{Data Analysis}

Data were edited, coded, cleaned, and entered into epidata version 3.1 and exported to SPSS version 21 software for analysis. Descriptive statistics was employed by using frequency and percentage, and put in text and tables. Logistic regression was used to identify the independent factors for PTSD. A variable with $p$-value less than 0.25 on bivariate analysis was taken into multivariate logistic regression model. Independent factors were declared at a $P$-value $<0.05$ cut-off point and strength of the association was assessed using AORs with their corresponding CIs at $95 \%$. A $p<0.05$ on multivariable logistic regression model was considered as statistically significant.

\section{Ethical Consideration}

The procedure was done in agreement with the Declaration of Helsinki. Ethical clearance permission letter was taken from the Review Board of Jimma University as the place was where part of my postgraduate study was carried out. After permission was given from prison administration, the purpose of the study was explained for participants. Then, written consent was got from participants prior to interview. Participation was completely voluntary, and the right to not participate in the study was also secured. Confidentiality was fully ensured in the study.

\section{Results}

\section{Socio-Demographic and Economic Characteristics}

A total of 411 prisoners participated with the response rate of $97.4 \%$. The mean and standard deviation of the participants' age in years was 29.24 and \pm 8.33 respectively. Nearly all were males ( $\mathrm{n}=404 / 411,98.3 \%)$, and the most common religion in this study was protestant ( $\mathrm{n}=268 / 411$, $65.2 \%$ ). Bench ethnicity comprises the majority of the participants. Socio-demographic information is provided in Table 1.

\section{Prevalence of Trauma and Comorbid Khat Use Disorder}

A total of $(n=293 / 411,71 \%),(n=79 / 411,19.2 \%)$, and $(n=152 / 411,37 \%)$ of the participants had life time trauma exposure, post-traumatic stress disorder, and khat use disorder, respectively. From the 293 prisoners with life time trauma exposure, ( $n=133 / 293,45 \%$ ) had khat use disorder and from the 79 prisoners with post-traumatic stress disorder, $(\mathrm{n}=67 / 79,85 \%)$ had khat use disorder. The most common types of trauma among prisoners with khat use disorder were exposure to threatened death, transportation accident, and exposure to war zone. From the participants with exposure to transportation accident $(\mathrm{n}=86 / 115,75 \%)$ had khat use disorder and from the respondents with exposure to threatened death $(\mathrm{n}=107 / 123,87 \%)$ had khat use disorder. In addition, from the total participants $(n=101 / 411,25 \%)$ were exposed to a war zone, and among them $(n=83 / 101,82 \%)$ had khat use disorder. Detailed information on specific trauma and comorbid khat use disorder is given in Table 2.

\section{Trauma and Crime-Related Factors}

All of the participants were convicted for at least three months or more. From the total participants, $(n=247 / 411$, $60 \%)$ were prisoned for two or less than two years and $(n=31 / 411,7.5 \%)$ were prisoned for lifelong. One third of the total participants $(\mathrm{n}=127 / 411,30.9 \%)$ were reconvicted prisoners; among them, $(\mathrm{n}=117 / 127,92 \%)$ had trauma exposure. Stealing $(n=174 / 411,42.3 \%)$, murder $(n=99 /$ $411,24.1 \%)$, and physical assault $(n=74 / 411,18 \%)$ were among the main reasons of incarceration. The majority of prisoners convicted for stealing, physical assault, sexual assault, and murder crime were exposed to trauma exposure. From the total participants, $(n=160 / 411,38.9 \%)$ had a family history of prison, and among them $(n=147 / 160$, 92\%) had exposure to trauma. Detailed information on crime related factors is given in Table 3.

\section{Clinical and Environmental-Related Factors}

From the total respondents, $(\mathrm{n}=171 / 411,41.6 \%)$ were screened positive for antisocial personality disorder, among them $(n=155 / 171,91 \%)$ were exposed to a traumatic life event. From the total respondents, $(n=48 /$ $411,11.7 \%$ ) had follow-up history of chronic medical illness. Tuberculosis, HIV/AIDS, and epilepsy were the most common reported medical cases among new prisoners. 
Table I Trauma and Socio-Economic and Demographic Features of the Sampled ( $\mathrm{N}=4 \mathrm{I}$ I) Prisoners in Bench Sheko and West Omo Correction Institution, Mizan Aman, Ethiopia, 2019

\begin{tabular}{|c|c|c|c|c|}
\hline \multirow[t]{2}{*}{ Variables } & \multicolumn{2}{|c|}{ Trauma Exposure } & \multirow{2}{*}{$\begin{array}{l}\text { Frequency } \\
\text { No }\end{array}$} & \multirow{2}{*}{$\begin{array}{l}\text { Percentage } \\
\%\end{array}$} \\
\hline & Yes (\%) & No (\%) & & \\
\hline \multicolumn{5}{|l|}{ Age } \\
\hline $18-24$ & $90(68)$ & $43(32)$ & 133 & 32.4 \\
\hline $25-44$ & I76 (7I) & $73(29)$ & 249 & 60.4 \\
\hline$\geq 45$ & $27(93)$ & $2(7)$ & 29 & 7.1 \\
\hline \multicolumn{5}{|l|}{ Occupation } \\
\hline Farmer & 130 (62) & $80(38)$ & 210 & 51.1 \\
\hline Unemployed & $10(63)$ & $6(37)$ & 16 & 3.9 \\
\hline Daily laborer & $68(82)$ & $15(18)$ & 83 & 20.2 \\
\hline Student & $27(82)$ & $6(18)$ & 33 & 8 \\
\hline Employed & $19(90)$ & $2(10)$ & 21 & 5.1 \\
\hline Driver & $25(100)$ & $0(0)$ & 25 & 6.1 \\
\hline Others & $14(61)$ & 9 (39) & 23 & 5.6 \\
\hline \multicolumn{5}{|l|}{ Ethnicity } \\
\hline Bench & $120(58)$ & $88(42)$ & 208 & 50.6 \\
\hline Sheko & $5 I(8 I)$ & $12(19)$ & 63 & 15.3 \\
\hline Amara & 47 (89) & $6(11)$ & 53 & 12.9 \\
\hline Kefa & 31 (97) & I (3) & 32 & 7.8 \\
\hline Dizi & $10(59)$ & $7(4 I)$ & 17 & 4.1 \\
\hline Mnit & $13(87)$ & $2(13)$ & 15 & 3.6 \\
\hline Others & $21(91)$ & $2(9)$ & 23 & 5.6 \\
\hline \multicolumn{5}{|l|}{ Sex } \\
\hline Male & $290(72)$ & II (28) & 404 & 98.3 \\
\hline Female & $3(43)$ & $4(57)$ & 7 & 1.7 \\
\hline \multicolumn{5}{|l|}{ Income } \\
\hline$<1200$ & $60(94)$ & $4(6)$ & 64 & 15.6 \\
\hline$\geq 1200$ & $233(64)$ & $124(36)$ & 347 & 84.4 \\
\hline \multicolumn{5}{|l|}{ Marital status } \\
\hline Married & $150(66)$ & $77(34)$ & 227 & 55.2 \\
\hline Single & $87(83)$ & $18(17)$ & 105 & 25.5 \\
\hline Divorced & $30(67)$ & $15(33)$ & 45 & 10.9 \\
\hline Separated & $21(72)$ & $8(28)$ & 29 & 7.2 \\
\hline Widowed & $5(100)$ & $0(0)$ & 5 & 1.2 \\
\hline \multicolumn{5}{|l|}{ Religion } \\
\hline Protestant & $160(60)$ & $108(40)$ & 268 & 65.2 \\
\hline Orthodox & $126(93)$ & $9(7)$ & 135 & 32.5 \\
\hline Muslim & $6(86)$ & I (14) & 7 & 1.7 \\
\hline Kalicha & I $(100)$ & $0(0)$ & 1 & 0.2 \\
\hline \multicolumn{5}{|l|}{ Education } \\
\hline Primary & $190(70)$ & $83(30)$ & 273 & 66.4 \\
\hline Secondary and above & $94(75)$ & $30(25)$ & 124 & 30.1 \\
\hline Unable to read and write & $9(64)$ & $5(36)$ & 14 & 3.4 \\
\hline
\end{tabular}

Notes: Other ethnicity includes; Tigre, Oromo, Wolaita, and Hadya, and other occupation includes; past or a list and those on pension.

Among the prisoners with chronic medical illness, $(\mathrm{n}=37 /$ $48,77 \%)$ had trauma exposure. From the total respondents, $(n=30 / 411,7.3 \%)$ reported that they were on follow up for having mental illness, and among them (n=26/30, $87 \%)$ had trauma exposure. Almost one third $(\mathrm{n}=130 / 411$, $32 \%)$ of participants reported that their family members 
Table 2 Specific Trauma and Comorbid Khat Use Disorder Among Prisoners of Bench Sheko and West Omozone, Mizan Aman Ethiopia, $(\mathrm{N}=41 \mathrm{I}), 2019$

\begin{tabular}{|c|c|c|c|c|}
\hline \multirow[t]{2}{*}{ Variables } & \multicolumn{2}{|c|}{ Khat Use Disorder } & \multirow{2}{*}{$\begin{array}{l}\text { Frequency } \\
\text { No }\end{array}$} & \multirow{2}{*}{$\begin{array}{l}\text { Percentage } \\
\%\end{array}$} \\
\hline & Yes (\%) & No (\%) & & \\
\hline \multicolumn{5}{|c|}{ Transportation accident } \\
\hline Yes & $86(75)$ & $29(25)$ & 115 & 27.7 \\
\hline No & $66(22)$ & $230(78)$ & 296 & 72.3 \\
\hline \multicolumn{5}{|c|}{ Physical assault } \\
\hline Yes & $55(79)$ & $15(21)$ & 70 & 16.8 \\
\hline No & $97(28)$ & $244(72)$ & 341 & 83.2 \\
\hline \multicolumn{5}{|c|}{ Exposure to death caused by others } \\
\hline Yes & $104(87)$ & $19(13)$ & 123 & 29.7 \\
\hline No & $48(17)$ & $240(83)$ & 288 & 70.3 \\
\hline \multicolumn{5}{|c|}{ Fire accident exposure } \\
\hline Yes & $17(77)$ & $5(13)$ & 22 & 5 \\
\hline No & $135(35)$ & $254(65)$ & 389 & 95 \\
\hline \multicolumn{5}{|c|}{ Exposure to warzone } \\
\hline Yes & $83(82)$ & $18(18)$ & 101 & 25 \\
\hline No & $69(22)$ & $24 \mid(88)$ & 310 & 75 \\
\hline \multicolumn{5}{|c|}{ Rape and other sexual assaults } \\
\hline Yes & $43(56)$ & $34(44)$ & 77 & 19 \\
\hline No & $109(33)$ & $225(67)$ & 334 & 81 \\
\hline \multicolumn{5}{|c|}{ Any other traumatic events } \\
\hline Yes & $124(57)$ & $94(43)$ & 218 & 53 \\
\hline No & $28(14)$ & $165(86)$ & 193 & 49.1 \\
\hline \multicolumn{5}{|c|}{ Post-traumatic stress disorder } \\
\hline Yes & $67(85)$ & $12(5)$ & 79 & 19.2 \\
\hline No & $85(26)$ & $247(74)$ & 332 & 80.8 \\
\hline \multicolumn{5}{|c|}{ Lifetime trauma exposure } \\
\hline Yes & $133(45)$ & $160(55)$ & 293 & 71 \\
\hline No & $19(16)$ & $99(84)$ & 118 & 29 \\
\hline
\end{tabular}

used alcohol, and among them $(\mathrm{n}=113 / 130,87 \%)$ were exposed to a traumatic life event. From the total participants, (n=186/411, 45.2\%) had childhood abuse and $(\mathrm{n}=160 / 411,39 \%)$ had experienced childhood neglect. More than half $(\mathrm{n}=215 / 411,52.3 \%)$ of respondents were under the category of poor social integration, and from them $(n=150 / 215,70 \%)$ had trauma experience (see Table 4).

\section{Trauma and Khat-Related Factors}

More than one out of three newly admitted prisoners $(\mathrm{n}=160 / 411,38.9 \%)$ had substance use disorder, and among them $(n=130 / 160,81 \%)$ were exposed to a traumatic life event. About half of the respondents $(n=209 / 411,50.9 \%)$ ever used khat, and among them $(n=170 / 209,81 \%)$ had trauma history. Nearly half of respondents ( $n=203 / 411,49.4 \%)$ were current khat users, and among them $(n=170 / 203,84 \%)$ had trauma exposure. From the total participants, $(\mathrm{n}=79 / 411,19.2 \%)$ were diagnosed with PTSD, and among them ( $\mathrm{n}=67 / 79,85 \%)$ had khat use disorder (see Table 5).

\section{Factors Associated with Trauma}

Multivariable logistic regression showed that the following variables were significantly associated with post-traumatic stress disorder: khat use disorder $(\mathrm{AOR}=5.3,95 \% \mathrm{CI}=2.4$ 11.8), antisocial personality disorder $(\mathrm{AOR}=2.8,95 \%$ $\mathrm{CI}=1.6-5.5)$, criminal recidivism $(\mathrm{AOR}=6,95 \% \mathrm{CI}=1.6-$ 22.4), and being a driver $(\mathrm{AOR}=2,95 \% \mathrm{CI}=1.2-3.3)$ (see Table 6). 
Table 3 Trauma and Crime Related Features of the Sampled ( $N=41$ I) Prisoners in Bench Shek oand West Omo Correctional Institution, Mizan Aman, Ethiopia, 2019

\begin{tabular}{|c|c|c|c|c|}
\hline \multirow[t]{2}{*}{ Variables } & \multicolumn{2}{|c|}{ Trauma Exposure } & \multirow{2}{*}{$\begin{array}{l}\text { Frequency } \\
\text { No }\end{array}$} & \multirow{2}{*}{$\begin{array}{l}\text { Percentage } \\
\%\end{array}$} \\
\hline & Yes (\%) & No (\%) & & \\
\hline \multicolumn{5}{|l|}{ Prior prison } \\
\hline Once & $50(69)$ & $22(3 I)$ & 72 & 17.8 \\
\hline Twice & $30(7 I)$ & $12(29)$ & 42 & 10.2 \\
\hline 3 and above & $8(67)$ & $4(33)$ & 12 & 2.9 \\
\hline No at all & $205(72)$ & $79(28)$ & 284 & 69.1 \\
\hline \multicolumn{5}{|l|}{ Crime type } \\
\hline Stealing & $120(69)$ & $54(3 I)$ & 174 & 42.3 \\
\hline Fighting & $46(62)$ & $28(38)$ & 74 & 18 \\
\hline Rape & $10(59)$ & $7(4 I)$ & 17 & 4.1 \\
\hline Sexual assault & $19(100)$ & $0(00)$ & 19 & 4.6 \\
\hline Homicide & $79(80)$ & $20(20)$ & 99 & 24.1 \\
\hline Robbery & $7(54)$ & $6(46)$ & 13 & 3.2 \\
\hline Dual marriage & $6(85)$ & I (I5) & 7 & 1.7 \\
\hline Others & $6(75)$ & $2(25)$ & 8 & 1.9 \\
\hline \multicolumn{5}{|l|}{ Reconviction } \\
\hline Yes & $117(92)$ & $10(8)$ & 127 & 30.9 \\
\hline No & $176(47)$ & $108(53)$ & 284 & 69.1 \\
\hline \multicolumn{5}{|c|}{ Misconduct in prior prison } \\
\hline Yes & $76(90)$ & $8(10)$ & 84 & 20.4 \\
\hline No & $217(66)$ & $110(34)$ & 327 & 79.6 \\
\hline \multicolumn{5}{|c|}{ Family history of prison } \\
\hline Yes & $147(92)$ & $13(8)$ & 160 & 38.9 \\
\hline No & $146(58)$ & $105(42)$ & 251 & 61.9 \\
\hline \multicolumn{5}{|l|}{ Physical abuse } \\
\hline Yes & $30(83)$ & $6(17)$ & 36 & 8.8 \\
\hline No & $263(70)$ & $112(30)$ & 375 & 91.2 \\
\hline \multicolumn{5}{|c|}{ Family history of divorce } \\
\hline Yes & $90(78)$ & $25(22)$ & 115 & 28 \\
\hline No & $203(69)$ & $93(3 \mathrm{I})$ & 296 & 72 \\
\hline
\end{tabular}

\section{Discussion}

This study assessed the relationship between khat use disorder and post-traumatic stress disorder among newly admitted prisoners with life time trauma exposure in Bench Shako and West Omo zone correctional institution, Mizan Aman, Ethiopia. According to this study, the overall prevalence of life time trauma exposure, post-traumatic stress disorder, and khat use disorder was $71 \%, 19.2 \%$, and $37 \%$, respectively. In addition, more than two out of three newly admitted prisoners were exposed to life time trauma exposure, and nearly one out of four prisoners developed post-traumatic stress disorder. About half of prisoners exposed to life time trauma had khat use disorder, and more than four out of five prisoners with post-traumatic stress disorder had khat use disorder. Another study conducted among Somali refugees in Nairobi, Kenya showed that the prevalence of life time trauma exposure, posttraumatic stress disorder, and khat use disorder was $98 \%$, $18.4 \%$ and $72 \%$ respectively. This study showed lower prevalence of life time trauma exposure and khat use disorder, and higher prevalence of PTSD than the study conducted among Somali refugees in Nairobi, Kenya. ${ }^{43}$ The difference could be due to: the difference in sample size, study setting, study population, and study design. The possible explanation for the higher prevalence of PTSD in this study could be due to the prison center is located 
Table 4 Trauma and Clinical Related Features of the Sampled $(\mathrm{N}=4 \mathrm{II})$ Prisoners in Bench Sheko and West Omo Correctional Institution, Mizan Aman, Ethiopia, 2019

\begin{tabular}{|c|c|c|c|c|}
\hline \multirow[t]{2}{*}{ Variables } & \multicolumn{2}{|c|}{ Trauma Exposure } & \multirow{2}{*}{$\begin{array}{l}\text { Frequency } \\
\text { No }\end{array}$} & \multirow{2}{*}{$\begin{array}{l}\text { Percentage } \\
\%\end{array}$} \\
\hline & Yes (\%) & No (\%) & & \\
\hline \multicolumn{5}{|c|}{ History of mental illness } \\
\hline Yes & $26(87)$ & $4(13)$ & 30 & 7.3 \\
\hline No & $267(70)$ & $114(30)$ & 381 & 92.7 \\
\hline \multicolumn{5}{|l|}{ Chronic physical illness } \\
\hline Yes & $37(77)$ & II (23) & 48 & 11.7 \\
\hline No & $256(7 I)$ & $107(29)$ & 363 & 88.3 \\
\hline \multicolumn{5}{|c|}{ Antisocial personality disorder } \\
\hline Yes & $155(9 \mid)$ & $16(9)$ & 171 & 41.6 \\
\hline No & $138(57)$ & $102(43)$ & 240 & 58.4 \\
\hline \multicolumn{5}{|c|}{ History of sexual abuse } \\
\hline Yes & $22(85)$ & $4(15)$ & 26 & 6.3 \\
\hline No & $271(70)$ & $114(30)$ & 385 & 93.7 \\
\hline \multicolumn{5}{|c|}{ Family history of alcohol } \\
\hline Yes & $113(60)$ & $17(40)$ & 130 & 31.6 \\
\hline No & $180(64)$ & $101(36)$ & 281 & 68.4 \\
\hline \multicolumn{5}{|l|}{ Social support } \\
\hline Poor & $150(70)$ & $65(30)$ & 215 & 52.3 \\
\hline Moderate & $35(66)$ & $18(34)$ & 53 & 12.9 \\
\hline Good & $108(75)$ & $35(25)$ & 143 & 34.8 \\
\hline \multicolumn{5}{|l|}{ Childhood trauma } \\
\hline Multiple & $100(8 I)$ & $23(19)$ & 123 & 29.9 \\
\hline Two & $124(77)$ & $38(23)$ & 162 & 39.4 \\
\hline one & $6(50)$ & $6(50)$ & 12 & 2.9 \\
\hline No trauma exposure & $63(55)$ & $51(45)$ & 114 & 27.7 \\
\hline
\end{tabular}

around a mining site where land slide is common, and it is also the area of civil war due to border conflict of Sheka and neighbor people. This study used a larger sample size $(n=411)$, the study participants were prisoners, and used a cross-sectional study design than the study done in Nairobi, which was on a small sample size $(n=48)$, the study participants were refugees, and used a qualitative study design than the current study. ${ }^{43}$

The prevalence of khat use disorder among prisoners with life time trauma exposure and PTSD was $45 \%$ and $85 \%$ respectively, and prisoners with khat use disorder had more than 5 times higher odds of association with PTSD than prisoners without khat use disorder. This finding was almost in line with the study conducted in Somali refugee population, where khat use disorder was linked with more life time trauma experience and PTSD symptoms than non-khat users. ${ }^{43,44}$ The possible explanation for the association could be due to prisoners with trauma experience might use khat to solve trauma-related psychological distress, depressed mood, low concentration, and anxious distress. $^{45}$ The self-medication hypothesis of substance use and trauma might also work for khat users with trauma exposure and post-traumatic stress disorder. As a result, prisoners with trauma exposure might use khat to deal with trauma-related negative emotional states. ${ }^{23}$

Problematic khat use was higher among prisoners with post-traumatic stress disorder and life time trauma exposure in Bench Shako and West Omo zone newly admitted prisoners. Although khat use disorder was positively associated with trauma exposure and post-traumatic stress disorder, it is difficult establish a cause-effect relationship. In our country, Ethiopia, people use khat during day time to have feelings of increased energy, to decrease fatigue, and to increase the alertness, and drink alcohol at night time to deal with sleep disturbance caused by khat consumption. ${ }^{3}$ It is common to use alcohol and khat simultaneously in our 
Table 5 Trauma and Substance Characteristics of respondents among prisoners of Bench Sheko and West Omo Zone, Mizan Aman Ethiopia, $(\mathrm{N}=41 \mathrm{I}), 2019$

\begin{tabular}{|c|c|c|c|c|}
\hline \multirow[t]{2}{*}{ Variables } & \multicolumn{2}{|c|}{ Trauma Exposure } & \multirow{2}{*}{$\begin{array}{l}\text { Frequency } \\
\text { No }\end{array}$} & \multirow{2}{*}{$\begin{array}{l}\text { Percentage } \\
\%\end{array}$} \\
\hline & Yes (\%) & No (\%) & & \\
\hline \multicolumn{5}{|c|}{ Khat use disorder } \\
\hline Yes & I $33(87.5)$ & $19(12.5)$ & 152 & 37 \\
\hline No & $160(62)$ & $99(38)$ & 259 & 63 \\
\hline \multicolumn{5}{|c|}{ Tobacco use disorder } \\
\hline Yes & $55(98)$ & I (2) & 56 & 13.6 \\
\hline No & $238(67)$ & 117 (33) & 355 & 86.5 \\
\hline \multicolumn{5}{|c|}{ Alcohol use disorder } \\
\hline Yes & $63(95)$ & $3(5)$ & 66 & 16.1 \\
\hline No & $230(67)$ & $115(33)$ & 345 & 83.9 \\
\hline \multicolumn{5}{|c|}{ Current khat use } \\
\hline Yes & $170(84)$ & $43(16)$ & 203 & 49.4 \\
\hline No & $123(59)$ & $85(4 I)$ & 208 & 50.6 \\
\hline \multicolumn{5}{|c|}{ Current tobacco use } \\
\hline Yes & $79(92)$ & $7(8)$ & 86 & 20.9 \\
\hline No & $214(66)$ & III (34) & 325 & 79.1 \\
\hline \multicolumn{5}{|c|}{ Current alcohol use } \\
\hline Yes & $75(82)$ & $16(18)$ & 91 & 22.1 \\
\hline No & $218(65)$ & $102(35)$ & 320 & 77.9 \\
\hline \multicolumn{5}{|c|}{ Ever khat use } \\
\hline Yes & $170(8 \mid)$ & $39(19)$ & 209 & 50.9 \\
\hline No & $123(6 \mid)$ & $79(39)$ & 202 & 49.1 \\
\hline \multicolumn{5}{|c|}{ Ever tobacco use } \\
\hline Yes & $60(7 I)$ & $25(29)$ & 85 & 20.7 \\
\hline No & $233(70)$ & $93(30)$ & 326 & 79.3 \\
\hline \multicolumn{5}{|c|}{ Ever alcohol use } \\
\hline Yes & $79(87)$ & $22(13)$ & 91 & 22.1 \\
\hline No & $214(67)$ & $106(33)$ & 320 & 77.9 \\
\hline \multicolumn{5}{|c|}{ Substance use disorder } \\
\hline Yes & $130(8 \mid)$ & $30(19)$ & 160 & 38.8 \\
\hline No & $163(65)$ & $87(35)$ & 251 & 68.4 \\
\hline
\end{tabular}

local scenario: khat is a known locally available stimulant which can disturb sleeping patterns, and people might selfmedicate themselves by using alcohol to initiate and sustain their sleeping pattern during night time. It is also well established that alcohol and trauma are also strongly related, ${ }^{32}$ and due to this, people might be exposed to a traumatic life event associated with alcohol misuse, and use khat in order to deal with trauma-related behavioral disturbances due to alcohol use.

This study also disclosed that having criminal recidivism had higher odds to have post-traumatic stress disorder than their counterparts. This result was almost in line with the study conducted in the USA. ${ }^{46}$ The reason might be due to prisoners with PTSD might have angry outbursts and aggressive behavior with no provocation as a part of their illness; which might enable them to be aggressive both verbally and physically towards people and objects; as a result, prisoners with PTSD were a risk for committing crime repeatedly. ${ }^{47}$

Many million people in Africa and other regions of the world use khat on a daily basis. ${ }^{2,3}$ It is well 
Table 6 Trauma and Associated Variables and Multivariate Logistic Regression Analysis of the Sampled (N=4II) Prisoners in Bench Sheko and West Omo Correctional Institution, Mizan Aman, Ethiopia, 2019

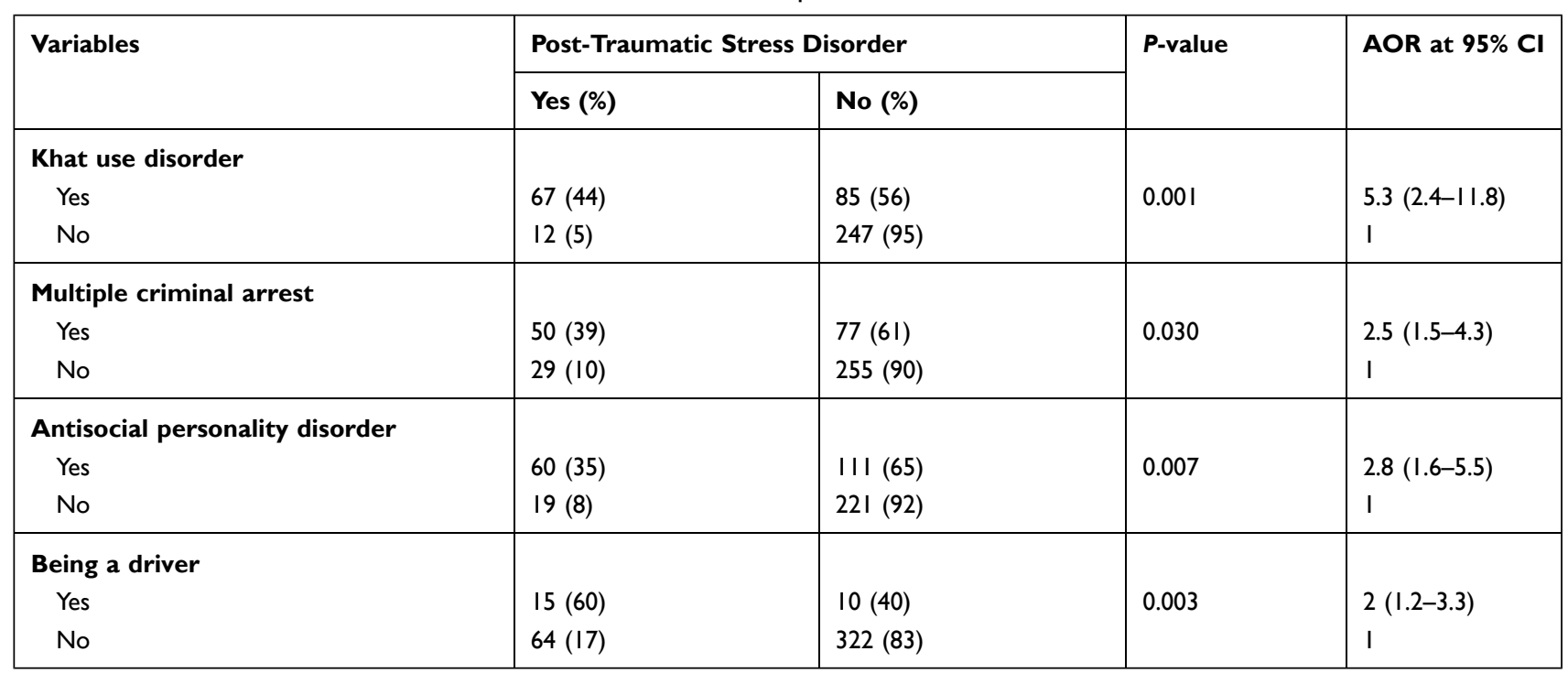

Note: I=reference category.

established that excessive khat chewing is associated with khat induced psychotic disorder, depression, suicidal, and homicidal behavior. ${ }^{5-7}$ This study also disclosed that khat use disorder is higher among prisoners with life time trauma exposure and post-traumatic stress disorder, and khat use disorder is positively and significantly associated with PTSD. Individuals with both PTSD and substance use disorder have a greater functional impairment and poor treatment outcome than individuals with either PTSD or substance use disorder alone. In this regard, introducing trauma and substance screening tools, diagnosis, treatment, and monitoring is recommended to prison health centers in Ethiopia. ${ }^{48}$ The integrated treatment model for both PTSD and khat use disorder was more effective than the traditional sequential treatment model. Furthermore, the integrated treatment model which includes exposure therapy and cognitive behavioral therapy was effective and well tolerated by patients; which can significantly reduce the symptoms of both PTSD and substance use disorder, and treat associated symptoms like depression, anxiety, and arousal symptoms. ${ }^{49}$ Despite prisoners suffering from multiple psychiatric disorders in Ethiopia, up to date the prison centers in Ethiopia have no mental health clinicians and service. This finding indicates to establish a mental health clinic in prison centers to early screen for trauma, PTSD, and khat use disorder and manage accordingly. Further longitudinal study is recommended to find the cause-effect relationship between post-traumatic stress disorder and khat use disorder.

\section{Limitations of the Study}

To the best of our knowledge, this study is the first among prisoners in Ethiopia or elsewhere to investigate the relationship between khat use disorder and trauma (PTSD). Yet, readers need to understand the following gaps while understanding this finding. Interviewer and recall bias, participants might deny for substance use history, and PTSD was screened by using a tool developed during DSM-IV. It is difficult to generalize for women prisoners and prisoners with life-threatening medical and psychiatric illnesses; since the number of women is insignificant and prisoners who were not able to give response due to underlying medical and psychiatric illness were excluded. Even though new prisoners reported that they have followup history of chronic medical illness, the medical record was not checked to confirm their physical and mental illness due to their follow up was outside the prison center. Moreover, this finding was not generalized to offenders stayed a long time in the correction center, since the study was conducted only among newly admitted prisoners.

\section{Conclusion}

Khat use disorder was higher among prisoners with trauma exposure and post-traumatic stress disorder, and khat use disorder was positively and significantly associated with PTSD. Therefore, the Federal Minister of Health need to 
integrate mental health clinic with addiction rehabilitation center with the already established health centers in all prison institutions in Ethiopia to work on preventive activities and to prepare early treatment and referral for detoxification and motivational interview for prisoners with khat use disorder, and to treat PTSD just after admission to prison center in order to prevent complications due to treatment delay.

\section{Abbreviations}

AOR, adjusted odds ratio, ASSIST, alcohol, smoking and substance involvement screening test, CI, confidence interval, SUD, substance use disorder, COR, crude odds ratio, DSM-V, Diagnostic and Statistical Manual of Mental Disorder Fifth edition, SPSS, Statistical Package for Social Science, USA, United States of America, WHO, World Health Organization, PTSD, post-traumatic stress disorder, ASPD, antisocial personality disorder.

\section{Data Sharing Statement}

It is possible to get the data set from Asrat Wolde with reasonable request.

\section{Ethics Approval and Consent to Participate}

The procedure was done in agreement with the Declaration of Helsinki. Ethical clearance permission letter was taken from the Review Board of Jimma University. After permission was given from prison administration, the purpose of the study was explained for participants. Then, written consent was obtained from the participants prior to the interview. Participation was completely voluntary, and the right to not participate in the study was also secured. Confidentiality was fully ensured in the study.

\section{Acknowledgments}

The author is thankful to Yonas Tesfaye, Yimenu Yitayih, Mebrat Thomas, Atarke Anjulo, respondents, and data collectors.

\section{Author Contributions}

The author made a significant contribution to the work reported, whether that is in the conception, study design, execution, acquisition of data, analysis and interpretation, or in all these areas; took part in drafting, revising or critically reviewing the article; gave final approval of the version to be published; agreed on the journal to which the article has been submitted; and agreed to be accountable for all aspects of the work.

\section{Funding}

No funding was received for this particular study.

\section{Disclosure}

The author reports no conflicts of interest for this work.

\section{References}

1. Kalix P. Cathaedulis, a plant that has amphet amine effects. Pharm World Sci. 1996;18:69-73. doi:10.1007/BF00579708

2. Odenwald M, Warfa N, Bhui K, Elbert T. The stimulant khatAnother door in the wall? A call for over coming the barriers. J Ethnopharmacol. 2010;132(3):6159. doi:10.1016/j.jep.2009.11.005

3. Rössler HC, Drogenin I, KatinderKneipe FAZ.2012. Availablefrom: www.faz.net. Accessed November 29, 2021.

4. Al-Habori M. The potential adverse effects of habitual use of Cathae dulis (khat). Expert Opin Drug Saf. 2005;4(6):1145-1154. doi:10. 1517/14740338.4.6.1145

5. Al-Hebshi NN, Al-Sharabi AK, Shuga-Aldin HM, Al-Haroni M, Ghandour I. Effect of khat chewing on period on tal pathogens in subging ival bio film From chronic per iodontitis patients. $J$ Ethnopharmacol. 2010;132(3):564-569. doi:10.1016/j.jep.2010. 08.051

6. Al-Motarreb A, Al-Habori M, Broadley KJ. Khat chewing, cardiovascular diseases and other internal medical problems: the current situation and directions for future research. $J$ Ethnopharmacol. 2010;132(3):540-548. doi:10.1016/j.jep.2010.07.001

7. Beckerleg S. East Africa and is courses on khat and sex. J Ethnopharmacol. 2010;132(3):600-606. doi:10.1016/j.jep.2010.08. 057

8. National Drug Intelligence Center. Intelligence Bulletin: Khat (Cathaedulis). Johnstown, PA: NDIC; 2003. Available from: http:// www.justice.gov/ndic/pubs3/3920/index.htm. AccessedFebruary 14, 2017.

9. Central Statistical Agency-CSA/Ethiopia and ICF. 2017 Ethiopia Demographic Health Survey 2016. AddisAbaba, Ethiopia: Central Statistical Agency and ICF; 2016. Available from: http://dhspro gram.com/pubs/pdf/FR328/FR328.pdf. Accessed November 29, 2021.

10. Harlow CW. Prior A Buse Reported by in Mates and Probationers, Bureau of Justice Statistics Selected Findings. US Department of Justice; 1999.

11. Stein DJ, Seedat S, Iversen A, Wessely S. Post-traumatic stress disorder: medicine and politics. Lancet. 2007;369:139-144. doi:10. 1016/S0140-6736(07)60075-0

12. Chilcoat HD, Breslau N. Posttraumatic stress disorder and drug disorders: Testing causal pathways. Arch Gen Psychiatry. 1998;55:913-917.

13. Dudeck M, Drenkhahn K, Spitzer C, et al. Traumatizationa nd mental distress in long-term prisoners in Europe. Punish Soci. 2011;13:403-423.

14. Naidoo S, Mkize DL. Prevalence of mental disorders in a prison population in Durban, SouthAfrica. J Psychiatry. 2012;15:30-35.

15. Kilpatrick DG, Resnick HS, Milanak ME, Miller MW, Keyes KM, Friedman MJ. National estimates of exposure to traumatic events and PTSD prevalence using DSM-IV and DSM-5 criteria. $J$ Trauma Stress. 2013;26(5):537-547.

16. Sadock BJ, Sadock VA, Ruiz P. Kaplan and Sadock's Synopsis of Psychiatry: Behavioral Sciences /Clinical Psychiatry. 11th ed. Philadelphia: Wolters Kluwer; 2014. 
17. Gibson LE, Holt JC, Fondacaro KM, Tang TS, Powell TA, Turbitt EL. An examination of antecedent traumas and psychiatric comorbidity among male in mates with PTSD. J Trauma Stress. 1999;12(3):473-484.

18. Carlson BE, Shafer MS. Traumatic histories and stressful life events of incarcerated parents: childhood and adult trauma histories. Prison J. 2010;90(4):475-493. doi:10.1177/0032885510382224

19. Jacobsen LK, Southwick SM, Kosten TR. Substance use disorders in patients with post traumatic stress disorder: a review of the literature. Am J Psychiatry. 2001;158(8):1184-1190.

20. Gros DL, Flanagan JC, Korte KJ, Mills AC, Brady KT, Back SE. Relations between social support, PTSD symptoms, and substance use in veterans. Psychol Addict Behav. 2016;30(7):764-770. doi:10.1037/adb0000205

21. Odenwald M, Semrau P. Reducing dropout among traumatized alcohol patients in detoxification treatment: a pilot intervention study. Eur Addict Res. 2012;18(2):54-63.

22. Waldrop AE, Back SE, Verduin ML, Brady KT. Triggers for cocaine and alcohol use in the presence and absence of post traumatic stress disorder. Addict Behav. 2007;32(3):634-639.

23. Boys A, Marsden J, Stillwell G, Hatchings K, Griffiths P, Farrell M. Minimizing respondent at trition in longitudinal research: practical implications from a cohort study of adolescent drinking. $J$ Adolesc. 2003;26(3):363-373.

24. Khantzian EJ, Treece C. DSM-III psychiatric diagnosis of narcotic addicts: recent findings. Arch Gen Psychiatry. 1985;42(11):10 67-1071.

25. Kaysen D, Dillworth TM, Simpson T, Waldrop A, Larimer ME, Resick PA. Domestic violence and alcoho luse:trauma-related symptoms and motives fo rdrinking. Addict Behav. 2007;32(6):1272-1283.

26. Cottler LB, Compton WM, Mager D, Spitznagel EL, Janca A. Post traumatic stress disorder among substance users from the general population. Am J Psychiatry. 1992;149(5):664-670.

27. Potthast N, Catani C. Traumaund Sucht: implikationenfürdie Psychotherapie. Sucht. 2012;58(4):227-235. doi:10.1024/0939-5911. a000191

28. Brown PJ, Wolfe J. Substance abuse and post-traumatic stress disorder comorbidity. Drug Alcohol Depend. 1994;35(1):51-59.

29. National Council on Alcohol is mand Drug Dependence Inc..Alcohol, drugs and crime. Available from: https:/www.ncadd.org/aboutaddiction/alcohol-drugs-andcrime. Accessed January 9, 2021.

30. The National Centeron Addiction and Substance Abuse at Colombi aUniversity. Behind BarsII: substance abuse and America's prison population. Available from: https:/www.centeronaddiction.org/addic tion-research/reports/behind-barsii-substance-abuse-and-america $\%$ E2\%80\%99s-prisonpopulation. Accessed January 9, 2021.

31. Yitayih Y, Soboka M, Tesfaye E, Abera M, Mamaru A, Adorjan K. Substance use disorder and associated factors among prisoners in a correctional institution in Jimma, Southwest Ethiopia: across-sectional study. BMC Psychiatry. 2018;18:314.

32. Yitayih Y, Soboka M, Tesfaye E, Abera M, Mamaru A, Adorjan K. Trauma exposure and alcohol use disorder among prisoners in Jimma Zone correctional institution, Southwest Ethiopia: across-sectional study. BMC Res Notes. 2019;12:748.

33. Yitayih Y, Soboka M, Tesfaye E, Abera M, Mamaru A, Adorjan K. A cross-sectional study of psychopathy and khat abuse among prisoners in the correctional institution in Jimma, Ethiopia. PLoS One. 2020;15 (1):e0227405.
34. Wolde A, Tesfaye Y, Yitayih Y. Psychopathy and associated Factors Among Newly Admitted Prisoners in Correctional Institution Located in Bench Sheko and West Omo Zone, South West Ethiopia: a Cross-Sectional Study. Psychol Res Behav Manage. 2021;14:261-273.

35. Fair, H, Walmsley, R. World prison population list; thirteenth edition. London: Institute for Crime \& Justice Policy Research; 2021. Available from: https://www.prisonstudies.org/sites/default/files/ resources/downloads/world_prison_population_list_13th_edition.pdf. Accessed December 8, 2021.

36. Weathers FW, Litz BT, Herman DS, Huska JA, Keane TM. The PTSD Checklist: Reliability, validity, \& diagnostic utility. Annu Meet Int Soc Trauma Stress Stud San Antonio, TX; 1993.

37. Weathers FW, Blake DD, Schnurr PP, Kaloupek DG, Max BP, Keane TM. Life events checklist for DSM-5 (LEC-5); Standard version. National Center for PTSD; 2013. Available from: https:/www.ptsd. va.gov/professional/assessment/documents/LEC5_Standard_Selfreport.PDF. Accessed December 8, 2021.

38. Blanchard EB, Jones-Alexander J, Buckley TC, Forneris CA. Psychometric properties of the PTSD Checklist (PCL). Behav Res Ther. 1996;34:669-673.

39. Humniuk R; WORLD HEALTH ORGANIZATION. The Alcohol, Smoking and Substance Involvement Screening Test (ASSIST); 2010.

40. Bøen H, Dalgard OS, Bjertness E. The importance of social support in the associations between psychological distress and somatic health problems and socio-economic factors among older adults living at home: a cross sectional study. BMC Geriatrics. 2012;12(1):27.

41. Gray MJ, Litz BT, Hsu JL, Lombardo TW. Psychometric properties of the life events checklist. Assessment. 2004;11(4):330-341. PMID:15486169. doi:10.1177/1073191104269954

42. American Psychiatric Association. Diagnostic and Statistical Manual of Mental Disorders, Fifth Edition. Arlington, VA: American Psychiatric Association; 2013.

43. WidmannM, WarsameAH, Mikulica J, et al. Khat use, PTSD and psychotic symptoms among Somali refugees in Nairobi - a pilot study. Frontiers Public Health. 2014;2:71. doi:10.3389/fpubh.2014.00071

44. Odenwald M, Hinkel H, Schauer E, et al. Use of khat and post-traumatic stress disorder as risk factors for psychotic symptoms: a study of Somali combatants. Soc Sci Med. 2009;69(7):1040-1048. doi:10.1016/j.socscimed.2009.07.020

45. Odenwald M, Lingenfelder B, Schauer M, et al. Screening for post-traumatic stress disorder among Somalie x-combatants: a validation study. Conf lHealth. 2007;1:10. doi:10.1186/1752-1505-1-10

46. Sadeh N, McNiel DE. Posttraumatic stress disorder increases risk of criminal recidivism among justice-involved persons with mental disorders. Cage j. 2014;42:6.

47. Marshall K, Abate A, Venata A. Posttraumatic stress symptoms and recidivism in serious juvenile offenders: testing the mediating role of future orientation. J Child Adolescent Trauma. 2018;13:33-45.

48. Gros DF, Flanagan JC, Korte KJ, Mills A, Brady KT, Sudie E. Back relations between social support, PTSD symptoms, and substance use in veterans. Psychol Addict Behav. 2016;30(7):764-770. doi:10.1037/ adb0000205

49. McCauley JL, Killeen T, Gros DL, Brady KT, Back SE. Back. Posttraumatic Stress Disorder and Co-Occurring Substance Use Disorders: Advances in Assessment and Treatment. Clin Psycho l (New York). 2012;19(3). doi:10.1111/cpsp.12006 


\section{Publish your work in this journal}

Neuropsychiatric Disease and Treatment is an international, peerreviewed journal of clinical therapeutics and pharmacology focusing on concise rapid reporting of clinical or pre-clinical studies on a range of neuropsychiatric and neurological disorders. This journal is indexed on PubMed Central, the 'PsycINFO' database and CAS, and is the official journal of The International Neuropsychiatric Association (INA). The manuscript management system is completely online and includes a very quick and fair peer-review system, which is all easy to use. Visit http://www.dovepress.com/testimonials.php to read real quotes from published authors.

Submit your manuscript here: https://www.dovepress.com/neuropsychiatric-disease-and-treatment-journal 